\title{
Probabilistic Characteristics of Intensive Short-Period Internal Waves in the Sea of Japan
}

\author{
M. V. Kokoulina, O. E. Kurkina, E. A. Rouvinskaya, A. A. Kurkin* \\ Nizhny Novgorod State Technical University n. a. R.E. Alekseev, Nizhny Novgorod, Russian Federation \\ *aakurkin@gmail.com
}

Purpose: The paper is aimed at studying the regional features of the internal waves' field in the Sea of Japan (the Peter the Great Bay) based on the field data, namely, determination of the internal waves' statistical characteristics that can be used to predict possibility of generating the waves of extreme amplitudes.

Methods and Results: The records of water temperature variability in the Peter the Great Bay (the depth at the point of measurements is $42 \mathrm{~m}$ ) obtained for October $11-20,2011$ were used as the initial data. Sampling frequency of the records was $1 \mathrm{~s}$ that permitted to analyze the shape of the short-period internal waves. The data on the salinity vertical distribution near the measurement point was also used. The law of the power density spectrum decay (as applied to the studied record) is well described by the Garrett - Munk model for the Sea of Japan zone being under consideration. The calculated temporal series of density were applied for obtaining the basic statistical characteristics including the statistical moments. Besides, empirical distribution for such parameters as the wave heights, periods and steepness and the wave slope amplitude was approximated by the log-normal distribution law and analyzed. The expected wave heights were forecasted using the Poisson statistics.

Conclusions: It is shown that the probabilistic characteristics of the internal waves are described well by the log-normal distribution. Based on repeatability of the internal waves' heights, probability of appearance of intensive disturbances is estimated. It is shown that within 10 days, occurrence of a short-period wave with the height not less than $7 \mathrm{~m}$ is guaranteed at the observation point at the $42 \mathrm{~m}$ depth.

Keywords: intensive internal waves, in situ data, probabilistic characteristics of extreme waves, shelf, Sea of Japan.

Acknowledgments: the represented results were obtained within the framework of the state task in the scientific activity field (theme No. FSWE-2020-0007) and at the support both of the President of RF grant on state support of the RF leading scientific schools NSh-2485.2020.5 and the grant of the President of Russian Federation to young scientists and postgraduates (SP-1225.2019.5).

For citation: Kokoulina, M.V., Kurkina, O.E., Rouvinskaya, E.A. and Kurkin, A.A., 2020. Probabilistic Characteristics of Intensive Short-Period Internal Waves in the Sea of Japan. Physical Oceanography, [e-journal] 27(5), pp. 501-513. doi:10.22449/1573-160X-2020-5-501-513

DOI: $10.22449 / 1573-160 X-2020-5-501-513$

(c) M. V. Kokoulina, O. E. Kurkina, E. A. Rouvinskaya, A. A. Kurkin, 2020

(C) Physical Oceanography, 2020

\section{Introduction}

The sea shelf zone is characterized by the most significant variability of hydrophysical fields associated, among other things, with the impact of intense internal waves, transforming and breaking down over the continental slope [1]. Most observations of solitary internal waves also occur in coastal areas (see, for example, the atlas of internal wave observations [2]: https://lmnad.nntu.ru/ru/igwatlas_map/).

The principal mechanism for short-period intense internal waves generation is the interaction of tidal currents with bottom irregularities [3]. Short-period internal 
waves are waves with periods from several minutes to several tens of minutes and with spatial scales from several hundred meters to several kilometers. Such waves contribute to the variability of hydrological characteristics and can affect the safety and economic efficiency of operations on the shelf [4-7]. For quantitative assessment of dangerous dynamic effects from short-period internal waves and their further consideration in engineering surveys associated with offshore construction, floating structures and underwater navigation, it is necessary to carry out regional occurrence probability estimates of internal waves of extreme amplitudes at various time intervals. Such assessments were started for certain areas of the White, Barents and Okhotsk seas in $[8,9]$. In the present paper, this issue was developed for the coastal zone of the Peter the Great Bay based on field records of internal wave fields in the Sea of Japan.

The paper is aimed at studying the regional features of the internal waves' field in the Sea of Japan based on the field data, namely, determination of the internal waves' statistical characteristics that can be used to predict possibility of generating the short-period internal waves of extreme amplitudes.

\section{Initial data}

We used the results of measurements of the temperature and salinity fields obtained during the 2011 autumn expedition in the shelf zone of the Sea of Japan. The measurement site map is shown in Fig. 1. The process of generation of internal wave packets is observed here during several months of the developed seasonal thermocline existence. The study of the dynamics of short-period internal waves of large amplitude was carried out in the "splash" zone for the main pycnocline, i.e. above the area of its contact with the bottom. The measurement technique and experimental equipment, as well as the results obtained, are described in detail in [10-12].

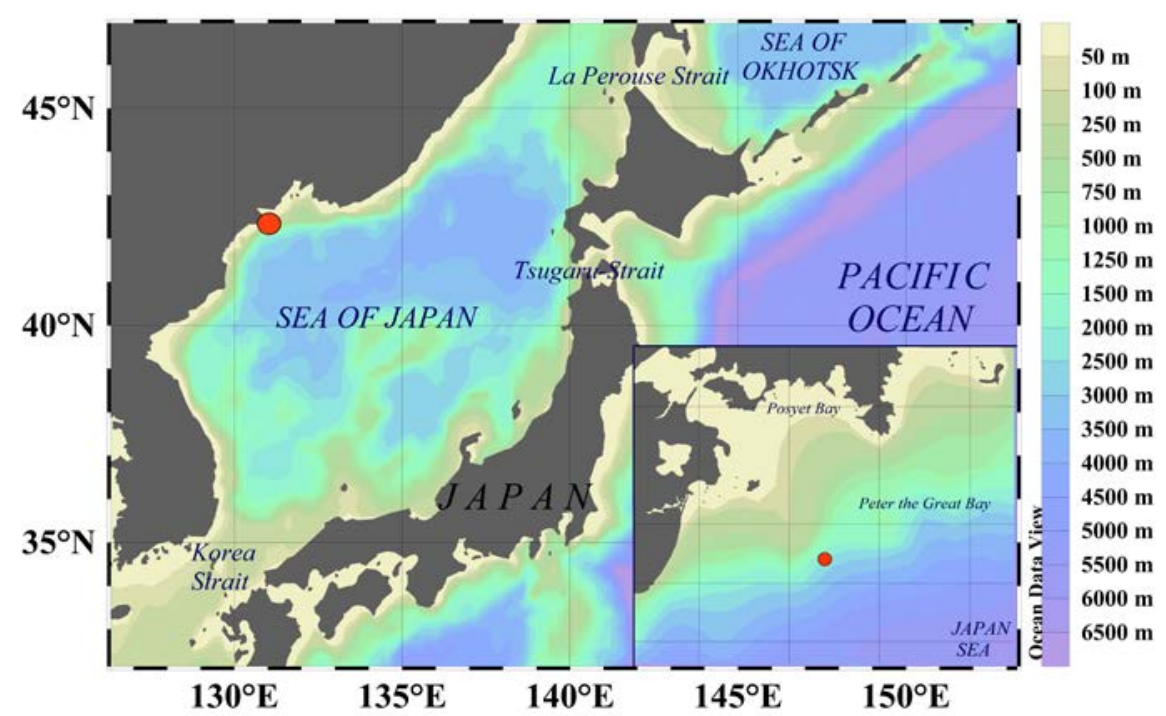

F i g. 1. Geographical location of the measurement site on the map of the Sea of Japan 
The experimental data was provided by the staff of the Laboratory of Statistical Hydroacoustics of the POI FEB RAS and included recording of temperature fluctuations using a thermal garland from October 11 (18:30) to October 20 (10:45) 2011 (data sampling rate was 1 s) (Fig. 2) and the vertical salinity profile (Fig. 3, a) based on RBR probe measurements on October 12 at $17: 40$ at about $500 \mathrm{~m}$ from the thermal garland.
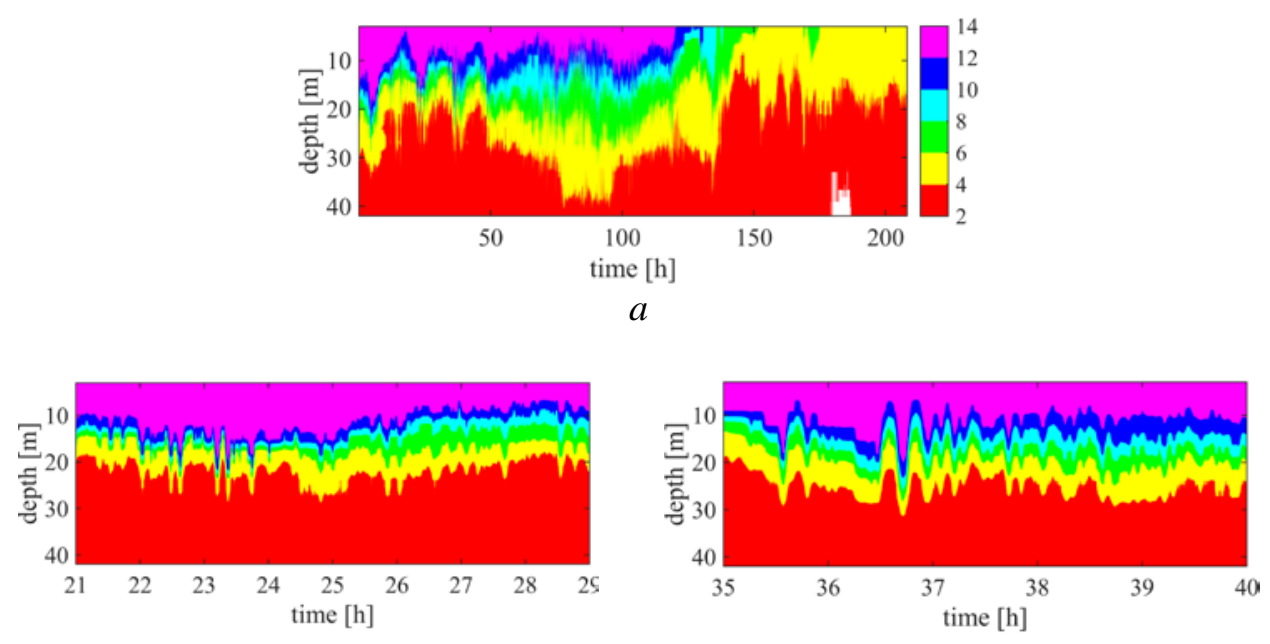

$b$

F i g. 2. Record of the temperature vertical profile $\left({ }^{\circ} \mathrm{C}\right)$ depending on time $(a)$ and its enlarged fragments $(b)$

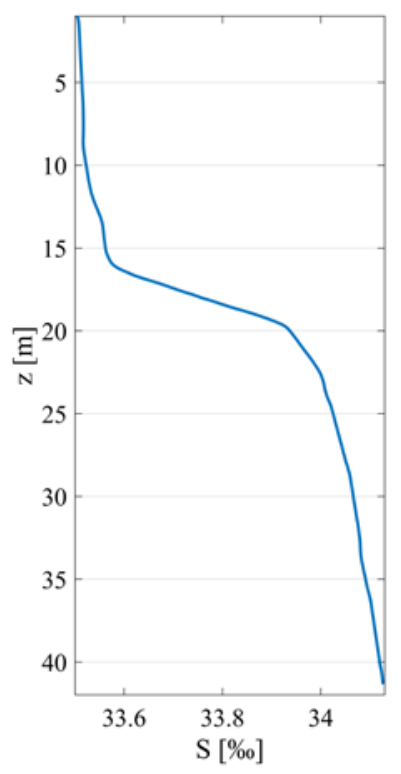

$a$

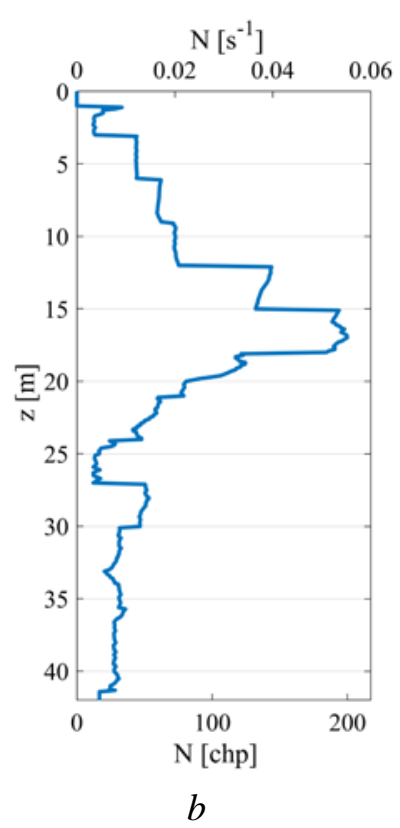

F i g. 3. Vertical profile of salinity (a) and Brunt - Väisälä frequency $(b)$ on October 12, 2011 at 17:40 (in 23 hrs and 10 min from the recording start) 
Fig. 2, a shows a record of the observed packets of internal waves in the seawater temperature field. A wave field is shown there; its semidiurnal and longer tidal disturbances are clearly distinguished. All isotherms look "cut" due to generated short-wave disturbances with a vertical amplitude of the order of 1$10 \mathrm{~m}$, with structure and composition being clearly visible on the enlarged fragments of the record in Fig. 2, $b$. In this case, the amplitude of the carrier long waves reaches $5-15 \mathrm{~m}$ at the $42 \mathrm{~m}$ depth at a given measurement point, which indicates their nonlinearity. The wave field of displacements of isotherms contains mainly the first vertical mode disturbances. The mode function has a maximum at the $17 \mathrm{~m}$ depth. The coefficients of quadratic and cubic nonlinearities in the framework of the weakly nonlinear theory of internal waves are negative, and the limiting amplitude of the solitary waves of the Gardner equation is approximately - $5.7 \mathrm{~m}$ (in more detail about the Sturm - Liouville problem for long linear internal waves and the determination of the nonlinearity coefficients can be found, for example, in [13]).

In the presented record (Fig. 2, a), three different wave modes are clearly distinguished. The first of them begins a few hours after the start of recording and lasts for about 50 hours. This mode is characterized by strong temperature stratification (temperature changes range from 2 to $14^{\circ} \mathrm{C}$ ) and the presence of a narrow, pronounced seasonal thermocline in the 10-20 m layer from the surface, the position of which is experiencing significant fluctuations with a semidiurnal period. These oscillations have a typical structure with winding wave fronts in the form of solibors. The next recording section with a duration of $50-120 \mathrm{~h}$ is characterized by a smooth temperature distribution over depth with heating of the lower layers; the long-wave oscillations of the isotherms here have a significantly longer period. Finally, the third concluding section of the recording (130-210 h) is characterized by a general cooling of the sea, so that the surface temperature does not exceed $8^{\circ} \mathrm{C}$ and, accordingly, the seawater density stratification is weaker, so waves with the highest amplitudes are possible (and observed). In all three recording areas, despite their differences, trains of intense short-period internal waves with significant amplitudes are clearly traced. Many of these disturbances have the typical form of solitary internal waves, predominantly of negative polarity (in the form of troughs), which agrees with the sign of the quadratic nonlinearity parameter. However, individual sections of the recording, including those shown in Fig. 2, b, contain localized oscillating wave packets similar in shape to internal breathers [14-18], the amplitude of which can reach 5-10 m.

\section{Spectral and statistical analysis of records}

For statistical analysis of wave disturbances in the field of displacements of isotherms, the longest isotherm $\mathrm{T}=4^{\circ} \mathrm{C}$, was selected; it is shown in Fig. 4. The original recording was smoothed by spectral filtering of noise with a period of less than $1 \mathrm{~min}$. It is seen that the range of curve fluctuations during the observation period is about $34 \mathrm{~m}$ with a total sea depth of $42 \mathrm{~m}$. 


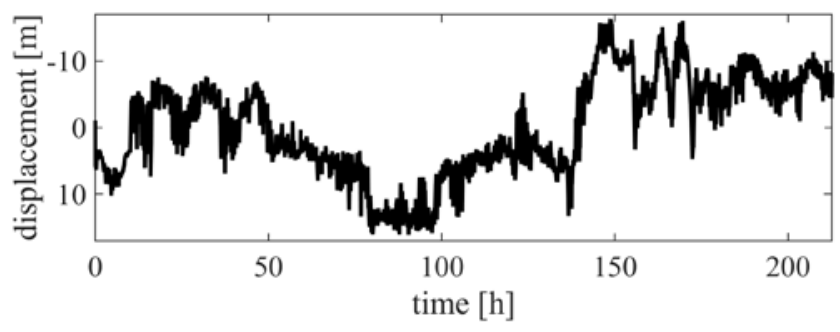

$a$
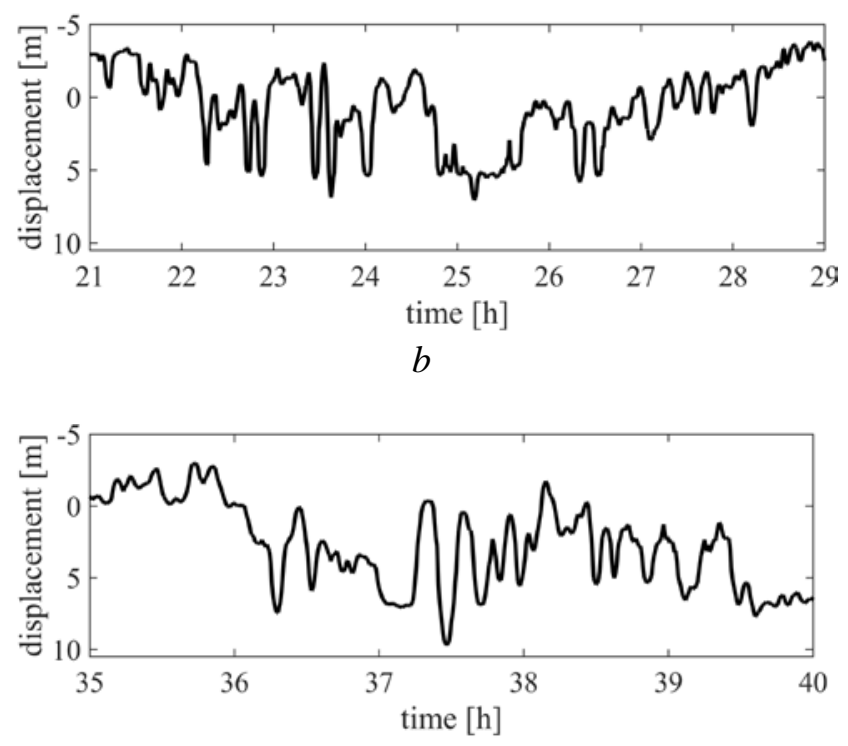

C

F i g. 4. Isotherm $4{ }^{\circ} \mathrm{C}(a)$ and zoom of its fragments $(b, c)$

The spectrum of temperature fluctuations, obtained during measurements from a moored buoy, with the possible exception of inertial and tidal frequencies, will be continuous in the entire frequency range [1]. The spectral density level falls according to an exponential law with an exponent from -1 to -4 , and more often from -2 to -3 . The amplitude spectrum (Fig. 5, $a$ ) of the isotherm fragment (over a time interval of 14-50 h from the start of recording, where the winding fronts of the semidiurnal tide waves are clearly visible) rapidly decreases with increasing frequency. A significant peak is observed at the frequency corresponding to the semidiurnal period.

Due to the fact that the spectra of temperature fluctuations in different areas of the World Ocean are similar, Garrett and Munk generalized them in the form of the following approximation for the spectral density of vertical displacements (see, for example, [1]):

$$
S(f, z)=\frac{C_{M} f_{i n} \sqrt{f^{2}-f_{i n}^{2}}}{N(z) f^{3}},
$$


where $C_{M}=204 \mathrm{~m}^{2} \cdot \mathrm{h}^{-1}$ is the empirical constant; all the frequencies $\left(f, f_{\text {in }}\right.$ and $\left.N\right)$ have the dimension cycle/h; $f_{\text {in }}=2 \Omega_{E} \sin \varphi$ id the inertial frequency $\left(\Omega_{E}-\right.$ Earth's rotation rate corresponding to a period of 24 hours, $\varphi$ is the geographic latitude of the observation point); $N(z)=\sqrt{\frac{g}{\rho_{0}(z)} \frac{d \rho_{0}(z)}{d z}}$ is the Brunt - Väisälä frequency on $z$-horizon, $g$ is the free fall acceleration, $\rho_{0}(z)$ is the vertical profile of seawater density, $z$-coordinate is down-directed , $z=0$ corresponds to the sea surface. Density $\rho_{0}(z)$ was calculated from the temperature and salinity profiles based on the TEOS-10 international Thermodynamic Equation of Seawater (http://www.teos-10.org/). The vertical profile of the Brunt - Väisälä frequency is shown in Fig. 3, $b$. The maximum values of $N(z)$ are achieved at 15-18 m depths and are more than $0.05 \mathrm{1} / \mathrm{s}$, which corresponds to the possible minimum periods of high-frequency internal waves of less than one minute.

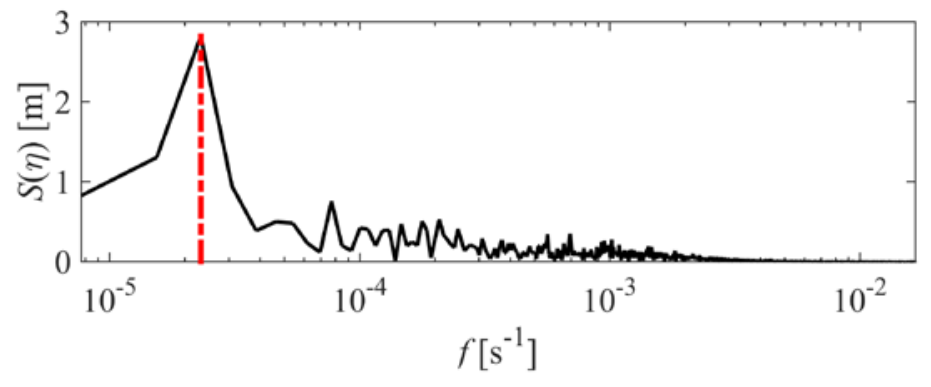

$a$

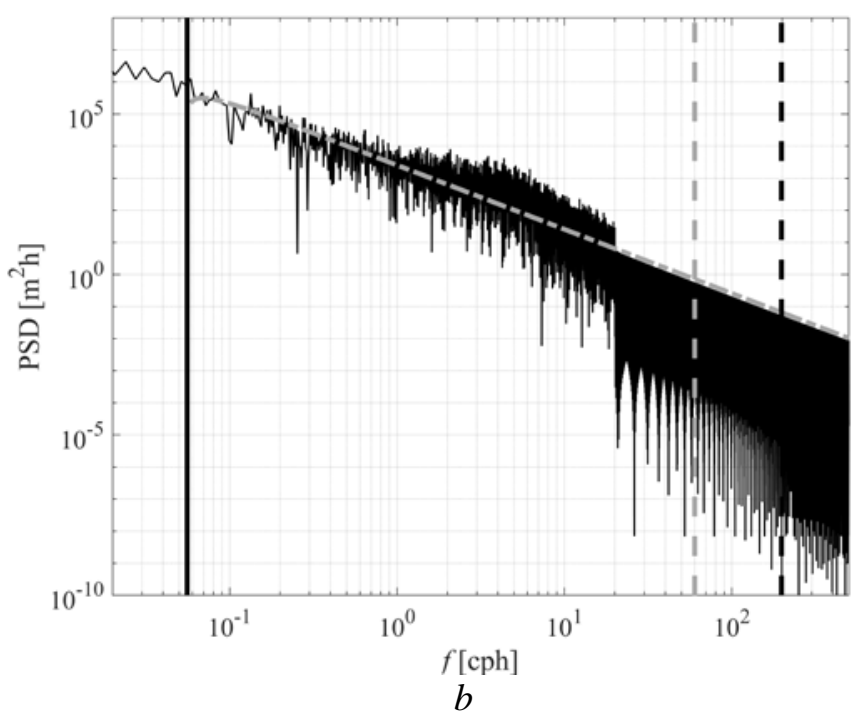

F i g. 5. Amplitude spectrum of the $4{ }^{\circ} \mathrm{C}$ isotherm vertical displacement within the time interval 14-50 hrs (red vertical line denotes frequency corresponding to the semi-diurnal period) $-a$; spectral density of the same wave field (blue dash-dot line shows the Garrett - Munk spectrum (1) for $z=25.5 \mathrm{~m}$, solid vertical line corresponds to the inertial frequency $f_{i n}$, blue vertical dash line - to the period $1 \mathrm{~min}$, black vertical dash line - to the maximum value of the Brunt - Väisälä frequency) $-b$ 
Fig. 5, $b$ shows the approximation of the temperature fluctuation spectrum by the Garrett - Munk model spectrum (1). For calculations by formula (1), the average level of the $4^{\circ} \mathrm{C}$ isotherm $z=25.5 \mathrm{~m}$ and $N(z)=0.0041 / \mathrm{s}$ was taken.

The distribution of the repeatability of the isotherm displacement ordinates shown in Fig. 4 is given in Fig. 6. It permits to get a general picture of the variability range of this quantity values. It can be seen that the distribution is multimodal (3 maxima of positive/negative values of the ordinates of the isotherm displacements are clearly distinguished: $\sim-6, \sim 4, \sim 13.5 \mathrm{~m}$ ), this can be interpreted in such a way that the observational data represent a superposition of several processes with different statistical characteristics.

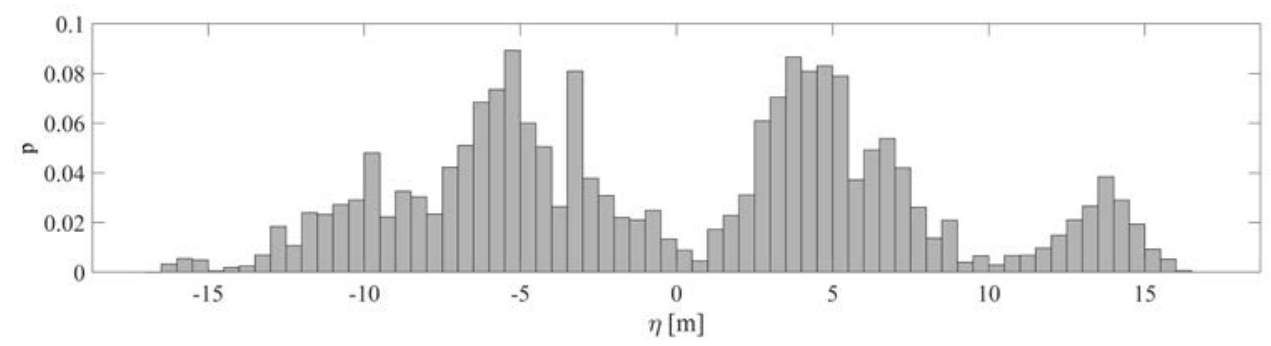

F i g. 6. Empirical distribution of the ordinates of the isotherm displacements

From the smoothed record of displacements of the $4^{\circ} \mathrm{C}$ isotherm, considered as a record of irregular waves, 1046 waves were selected. The height of the wave $(H)$ is estimated as the average value between the heights of its front and rear slopes, the period $(T)$ of each wave is determined as the time interval between the adjacent contour minima. Waves less than $0.5 \mathrm{~m}$ high were not taken into account.

Below the values of the wave heights and the corresponding periods are analyzed. Fig. 7 shows the distribution of these values within the original record.
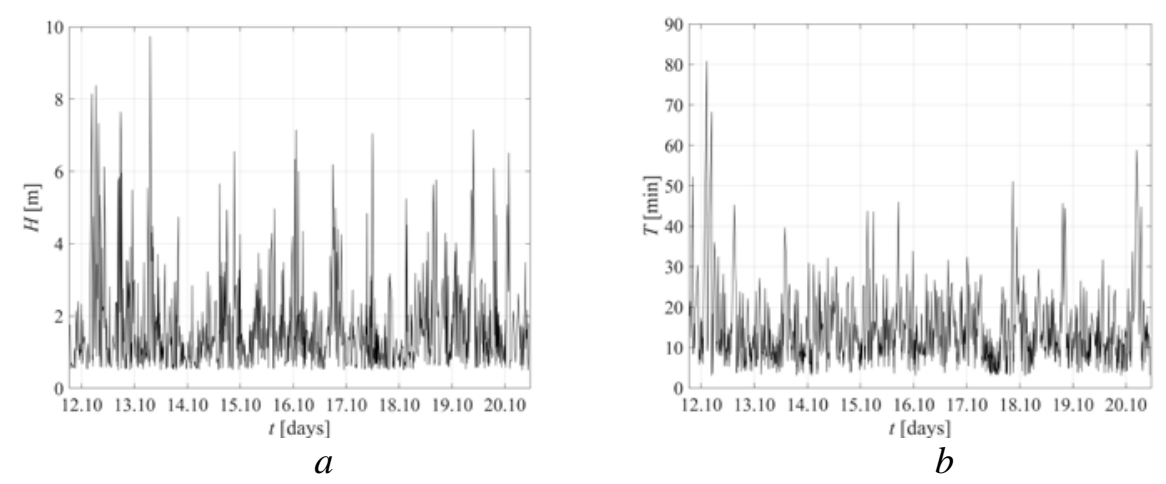

F i g. 7. Time-dependence of the wave heights ( $a$ ) and periods $(b)$

The frequency distributions of the heights $(H)$ and periods $(T)$ of waves in the record of the $4^{\circ} \mathrm{C}$ isotherm displacement are shown in Fig. 8. Note that the heights of all waves considered are ranged within $0.5-10 \mathrm{~m}$, the periods within 2-60 min. Mean wave height is $1.6 \mathrm{~m}$, standard deviation of height is $1.12 \mathrm{~m}$; the mean period is 12 minutes, the standard deviation is 7.4 minutes. Both PHYSICAL OCEANOGRAPHY VOL. 27 ISS. 5 (2020) 
distributions are well approximated by a theoretical log-normal distribution law with a probability density

$$
g(a)=\frac{1}{a \sigma \sqrt{2 \pi}} \exp \left[-(\ln a / \mu)^{2} / 2 \sigma^{2}\right],
$$

where $a$ is the value analyzed with the parameters $\mu=0.27 \mathrm{~m}, \sigma=0.63$ for wave heights $(H)$ and $\mu=2.3 \mathrm{~min}, \sigma=0.58$ for periods $(T)$.

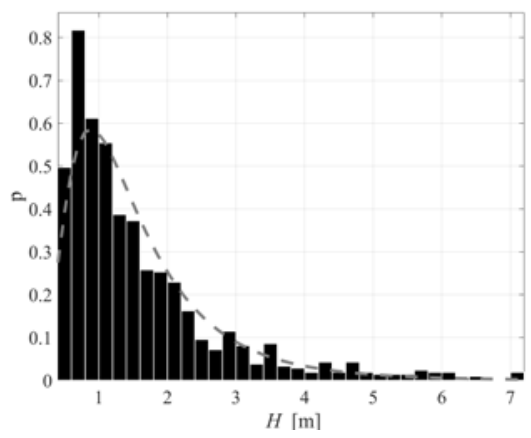

$a$

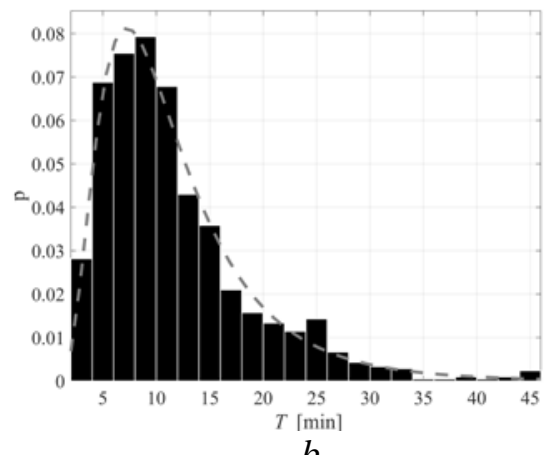

$b$

F i g. 8. Distributions of the wave heights $(a)$ and periods $(b)$ and their approximations (dash line) by the log-normal distribution law (2)

Pearson's criterion also confirms that the distributions of heights and periods of waves obey the logarithmically normal law, $\chi^{2}$ for heights and periods is 10.93 and 21.52, respectively, with a critical value of 68.7 .

Fig. 9, showing experimental data on wave heights in the coordinates of a lognormal distribution (in these coordinates, the lognormal curve becomes a straight line, the vertical axis becomes nonlinear), demonstrates that the greatest deviations are observed in the zone of low wave heights and periods.

In the classical sense, the wave steepness is the ratio of the wave height to its length, and the amplitude of the wave slope angle (local steepness) is the maximum value of the angle at the points of the wave profile. However, since the record in time (the wave period, not the length is known) is analyzed, then to find these characteristics, it is necessary to introduce dimensionless variables that determine the abscissa and ordinate axes: $t^{*}=t / T^{*}, z^{*}=z / H^{*}$, where $t$ and $z$ are the values of the recording time and isotherm ordinates, respectively, $T^{*}$ and $H^{*}$ are modal values for log-normal curves that approximate the distribution of heights and wave periods. The range of variation of the obtained wave steepness $\delta=H T^{*} /\left(H^{*} T\right)$ and the amplitude of the wave slope angle $\alpha$ for the $4^{\circ} \mathrm{C}$ isotherm are shown in Fig. 10 . Note that the wave steepness has small values, which are ranged within $0-10$, and the wave slope angle amplitude is in the range of $0-4.5^{\circ}$. Both distributions are also well approximated by the theoretical log-normal distribution law (2) with the parameters $\mu=1.29, \sigma=1.07$ for the wave steepness $\delta$ and $\mu=0.86^{\circ}, \sigma=0.51$ for the amplitude of the wave slope $\alpha$. 

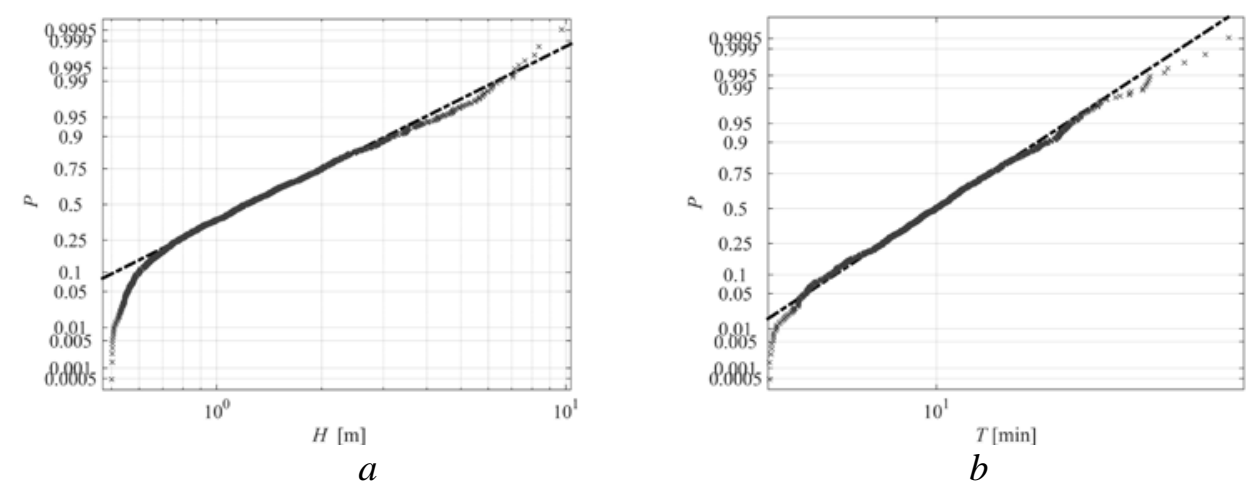

F i g. 9. Comparison of distributions of the wave heights $(a)$ and periods $(b)$ with the log-normal ones (solid line), crosses denote real data
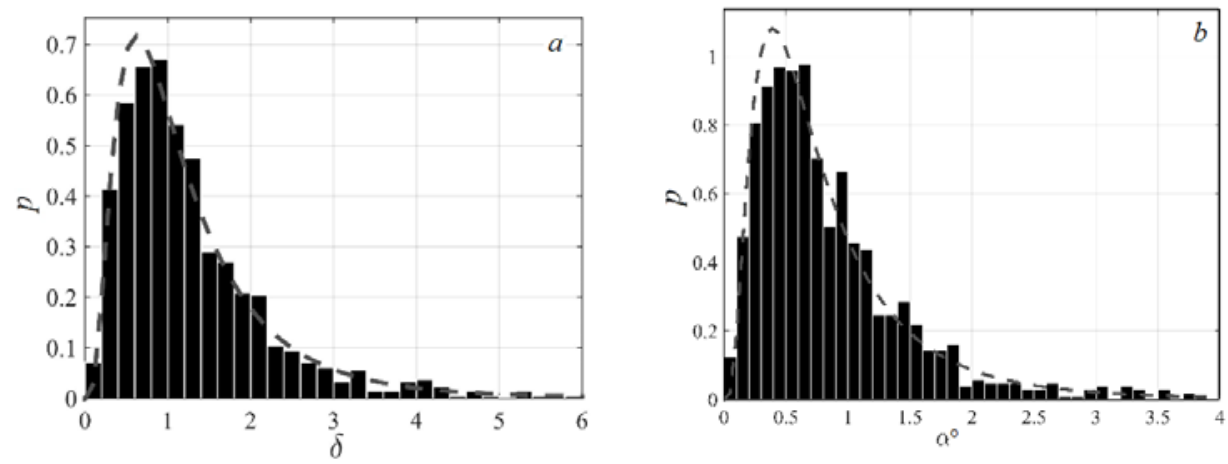

F i g. 10. Distributions of wave steepness $(a)$ and wave slope angle amplitude $(b)$, and their approximations (dash line) by the log-normal distribution law (2)

The curve of the probability of wave heights, obtained in accordance with the lognormal distribution (2) law, is shown in Fig. 11. The modal level is $0.6-0.9 \mathrm{~m}$, the median level is $1.31 \mathrm{~m}$, the significant wave height is $2.8 \mathrm{~m}$. The correspondence of the wave height and the probability levels for the displacement field of the $4^{\circ} \mathrm{C}$ isotherm is given in Table 1

T a b l e 1

Table of wave height and corresponding exceedance probability levels for $4^{\circ} \mathrm{C}$ isotherm displacement field

$H, \mathrm{~m}$

Probability of

exceeding, \%
1

65.5
3

10
5

1.5
10

0.06 


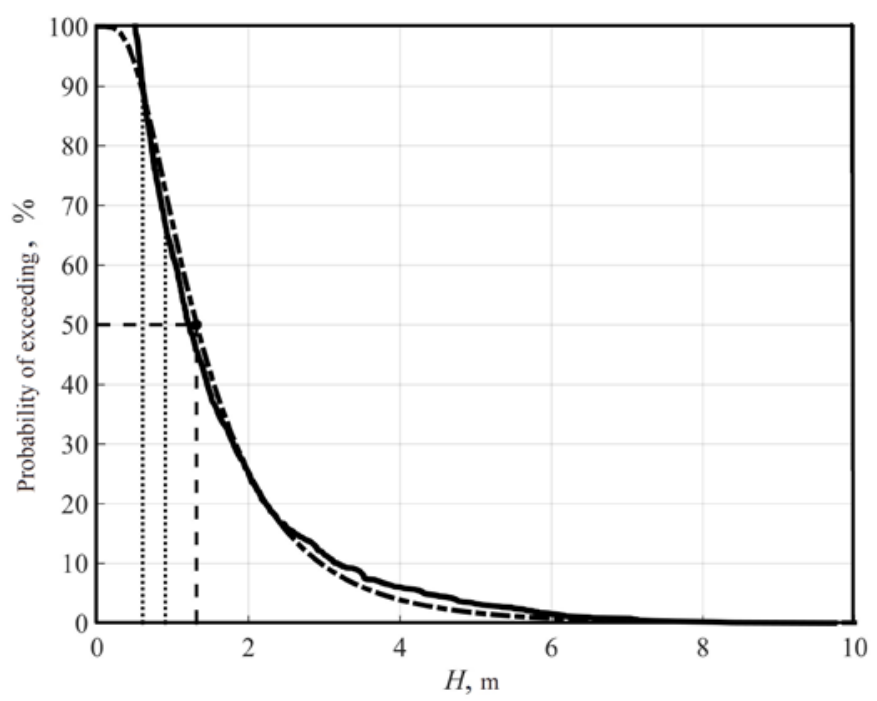

F i g. 11. Exceedance probability for the wave heights for the displacement of the $4{ }^{\circ} \mathrm{C}$ isotherm. Solid line is the empirical curve, dash-dot line represents the theoretical function of the level excess probability corresponding to the log-normal law (2), dash line denotes the median value, and the dotted lines - the modal level range

As a hazard estimation associated with the level of wave height $h$, a value equal to the probability of exceeding this level is used:

$$
R(h)=1-P_{0}(>h)=1-\exp [-\varphi(h) t]
$$

in accordance with the description of the Poisson sequence of events. The function $\varphi(h)$ in the exponent is called the wave height repeatability function:

$$
\varphi(h)=\frac{N(\text { height } \geq \mathrm{h})}{T},
$$

which, by definition, is equal to the average frequency of events with a wave height at a given location equal to or greater than the threshold value $h$. This function is monotonically decreasing and, for sufficiently larger $h$, is well approximated by an exponential (Fig. 12):

$$
\varphi(h)=f_{h} \exp \left[-h / H^{*}\right] .
$$

The repeatability function of the internal waves heights depends on two empirical parameters that should be selected from the field data: $f_{h}$ has the physical meaning of the frequency of large waves, the $H^{*}$ parameter is the so-called characteristic height, has the dimension of the amplitude of the considered wave field. Both parameters are regional and depend on the characteristics of the shelf and the characteristics of hydrology. In our case, $f_{h}=58.11 /$ day, $H^{*}=1.1 \mathrm{~m}$. 


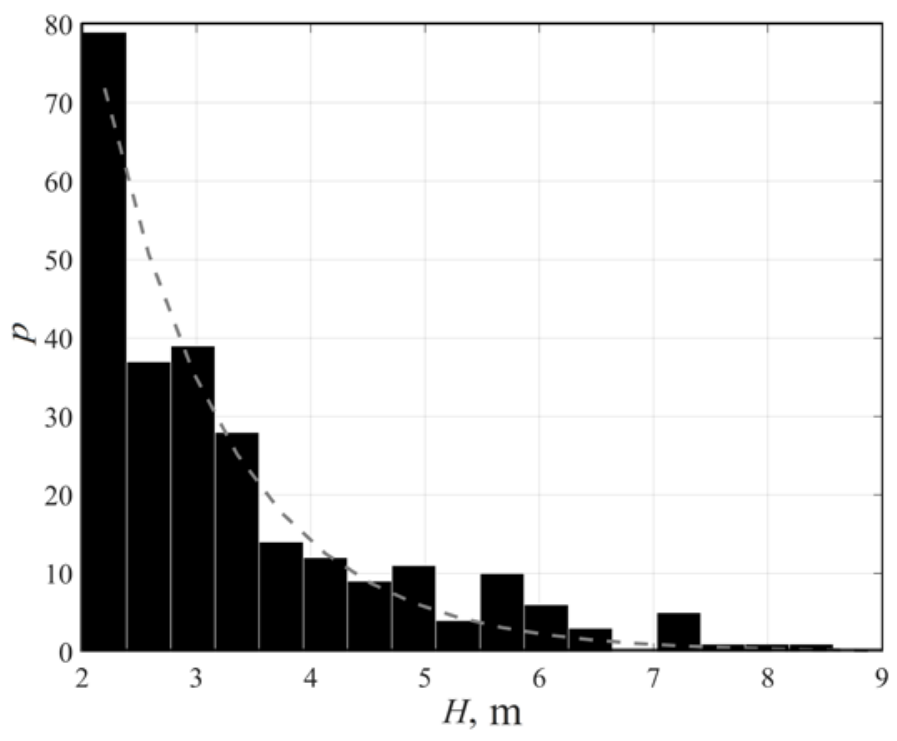

F i g. 12. Distribution of wave heights and its approximation (dash line) by the exponential distribution law (3)

The expected height over a time period, e.g. that of 10 days, is calculated using the following formula

$$
h_{10 \text { days }}=H^{*} \ln \left(10 \text { days } \cdot f_{h}, 1 / \text { day }\right) \text {. }
$$

Estimates of the expected heights of internal waves for periods of 10, 30, 60 and 90 days are shown in the Table. Of course, a long-term forecast of wave characteristics made on the basis of a 9-day record should be considered as a preliminary one, which further needs to be verified on the basis of longer records.

Expected heights of the internal waves (m) which were at least once exceeded during the specified time period

\begin{tabular}{c|c}
\hline Time period, days & $\begin{array}{c}\text { Expected height } h, \mathrm{~m} \\
\text { (95\%-confidence interval) }\end{array}$ \\
\hline 10 & $7.04(5.12 ; 8.91)$ \\
30 & $8.25(6.1 ; 10.36)$ \\
60 & $9.02(6.72 ; 11.28)$ \\
90 & $9.47(7.08 ; 11.81)$ \\
\hline Maximum wave height (based on observations), $\mathrm{m}$ & 9.73 \\
\hline
\end{tabular}




\section{Conclusion}

During the present study, a time series of temperature profiles with a length of about $210 \mathrm{~h}$, obtained in the shelf zone of the Sea of Japan based on instrumental observations for 9 days in October 2011, was processed. More than 1000 shortperiod internal waves with heights of 1-10 m were identified in the record, with a total depth at the measurement point of $42 \mathrm{~m}$. It is shown that the probabilistic characteristics of internal waves are described well by a log-normal distribution. Based on the frequency distribution of the heights of internal waves, the probability of the appearance of intense disturbances was estimated.

\section{REFERENCES}

1. Morozov, E.G., 2018. Oceanic Internal Tides: Observations, Analysis and Modeling. Cham: Springer, 304 p. doi:10.1007/978-3-319-73159-9

2. Epifanova, A.S., Rybin, A.V., Moiseenko, T.E., Kurkina, O.E., Kurkin A.A. and Tyugin, D.Yu., 2019. Database of Observations of the Internal Waves in the World Ocean. Physical Oceanography, 26(4), pp. 350-356. doi:10.22449/1573-160X-2019-4-350-356

3. Vlasenko, V., Stashchuk, N. and Hutter, K., 2005. Baroclinic Tides: Theoretical Modeling and Observational Evidence. Cambridge: Cambridge University Press, pp. 335-347. https://doi.org/10.1017/CBO9780511535932

4. Chakrabarti, S.K., 2005. Handbook of Offshore Engineering (in two vol.). Amsterdam: Elsevier. URL: https://www.academia.edu/10659382/Chakrabarti_2005_Handbook_of_Offshore_Eng [Accessed: 09 September 2020].

5. Osborne, A., 2010. Nonlinear Ocean Waves and the Inverse Scattering Transform. Amsterdam: Academic Press, 944 p.

6. Song, Z.J., Teng, B., Gou, Y., Lu, L., Shi, Z.M., Xiao, Y. and Qu, Y., 2011. Comparisons of Internal Solitary Wave and Surface Wave Actions on Marine Structures and Their Responses. Applied Ocean Research, 33(2), pp. 120-129. https://doi.org/10.1016/j.apor.2011.01.003

7. Stöber, U. and Moum, J.N., 2011. On the Potential for Automated Realtime Detection of Nonlinear Internal Waves from Seafloor Pressure Measurements. Applied Ocean Research, 33(4), pp. 275-285. doi:10.1016/j.apor.2011.07.007

8. Svergun, E.I. and Zimin, A.V., 2017. Forecast of the Occurrence of Intense Internal Waves in the White and Barents Seas According to Expeditionary Research. Fundamentalnaya $i$ Prikladnaya Gidrofizika, 10(2), pp. 13-19. doi:10.7868/S2073667317020022 (in Russian).

9. Zimin, A.V. and Svergun, E.I., 2018. Short-Period Internal Waves in the Shelf Areas of the White, Barents and Okhotsk Seas: Estimation of the Extreme Heights Occurrence and Dynamic Effects in the Bottom Layer. Fundamentalnaya i Prikladnaya Gidrofizika, 11(2), pp. 66-72. doi:10.7868/S2073667318040081 (in Russian).

10. Yaroshchuk, I.O., Leontyev, A.P., Kosheleva, A.V., Samchenko, A.N., Pivovarov, A.A., Khrapchenkov, F.F., Shvyrev, A.N. and Yaroshchuk, E.I., 2013. Experimental Studies of Internal Waves in the Sea of Japan Coastal Zone. Podvodnye Issledovaniya $i$ Robototekhnika = Underwater Investigations and Robotics, 1(15), pp. 37-44 (in Russian).

11. Yaroshchuk, I.O., Leont'ev, A.P., Kosheleva, A.V., Pivovarov, A.A., Samchenko, A.N., Stepanov, D.V. and Shvyryov, A.N., 2016. On Intense Internal Waves in the Coastal Zone of the Peter the Great Bay (the Sea of Japan). Russian Meteorology and Hydrology, 41(9), pp. 629-634. https://doi.org/10.3103/S1068373916090053

12. Samchenko, A.N., Yaroshchuk, I.O. and Kosheleva, A.V., 2018. Internal Gravity Waves in the Coastal Zone of the Sea of Japan According to the Natural Observations. Regional Studies in Marine Science, 18, pp. 156-160. https://doi.org/10.1016/j.rsma.2018.02.004

13. Kurkina, O., Rouvinskaya, E., Talipova, T. and Soomere, T., 2017. Propagation Regimes and Populations of Internal Waves in the Mediterranean Sea Basin. Estuarine, Coastal and Shelf Science, 185, pp. 44-54. doi:10.1016/j.ecss.2016.12.003 
14. Lamb, K.G., Polukhina, O., Talipova, T., Pelinovsky, E., Xiao, W. and Kurkin, A., 2007. Breather Generation in Fully Nonlinear Models of a Stratified Fluid. Physical Review E, 75(4), 046306. https://doi.org/10.1103/PhysRevE.75.046306

15. Ruvinskaya, E.A., Kurkina, O.E., Kurkin, A.A. and Naumov, A.A., 2015. Transport of Particles at the Propagation of Breathers of Internal Gravity Waves. Fundamentalnaya $i$ Prikladnaya Gidrofizika, 8(3), pp. 53-61 (in Russian).

16. Rouvinskaya, E., Talipova, T., Kurkina, O., Soomere, T. and Tyugin, D., 2015. Transformation of Internal Breathers in the Idealized Shelf Sea Conditions. Continental Shelf Research, 110, pp. 60-71. https://doi.org/10.1016/j.csr.2015.09.017

17. Rouvinskaya, E., Kurkina, O., Kurkin, A. and Lobovikov, P., 2017. Internal Breathers' Loads on Marine Facilities. In: Mediterranean Coastal Foundation, 2017. 13th International MEDCOAST Congress on Coastal and Marine Sciences, Engineering, Management and Conservation, MEDCOAST 2017. Mugla, Turkey: MEDCOAST. Vol. 2, pp. 1191-1202.

18. Rouvinskaya, E., Kurkina, O., Kurkin, A. and Lobovikov, P., 2017. Particle Transport by Internal Breathers. In: Mediterranean Coastal Foundation, 2017. 13th International MEDCOAST Congress on Coastal and Marine Sciences, Engineering, Management and Conservation, MEDCOAST 2017. Mugla, Turkey: MEDCOAST. Vol. 2, pp. 1179-1190.

About the authors:

Maria V. Kokoulina, Engineer, Nizhny Novgorod State Technical University n. a. R. E. Alekseev (24 Minin St., Nizhny Novgorod, 603950, Russian Federation), ORCID ID: 0000-0001-5890-3649, ResearcherID: AAD-7131-2019, kokoulinamaria97@gmail.com

Oksana E. Kurkina - Leading Researcher, Associate Professor of the Applied Mathematics Department, Nizhny Novgorod State Technical University n. a. R. E. Alekseev (24 Minin St., Nizhny Novgorod, 603950, Russian Federation), Ph. D. (Phys.-Math.), ORCID ID: 0000-0002-4030-2906, ResearcherID G-9577-2011, Oksana.Kurkina@mail.ru

Ekaterina A. Rouvinskaya, Researcher, Nizhny Novgorod State Technical University n. a. R. E. Alekseev (24 Minin St., Nizhny Novgorod, 603950, Russian Federation), Ph. D. (Phys.-Math.), ORCID ID: 0000-0002-3858-1731, ResearcherID: A-2868-2014, e.rouvinskaya@gmail.com

Andrey A. Kurkin - Chief Researcher, Head of the Applied Mathematics Department, Scientific Supervisor of Laboratory of Modeling of Natural and Anthropogenic Disasters, Nizhny Novgorod State Technical University n. a. R. E. Alekseev (24 Minin St., Nizhny Novgorod, 603950, Russian Federation), Dr. Sci. (Phys.-Math.), Professor, ORCID ID: 0000-0003-3828-6406, ResearcherID: A-1972-2014, aakurkin@gmail.com

Contribution of the co-authors:

Maria V. Kokoulina - development and debugging of algorithms for the problem solution

Oksana E. Kurkina - the problem formulation and setting, qualitative and quantitative analysis of the results

Ekaterina A. Rouvinskaya - preparation of the article text and graphic materials, participation in the discussion of article materials

Andrey A. Kurkin - scientific supervision, critical analysis and revision of the text

All the authors have read and approved the final manuscript.

The authors declare that they have no conflict of interest. 